\title{
ZnO Nanowire/N719 dye/Polythiophene-SWNT nanocomposite solid state dye sensitized solar cells
}

\author{
S. AbdulAmohsin ${ }^{1}$, Sabah Mohammed Mlkat al Mutoki ${ }^{2}$ M. Mohamed ${ }^{1}$ \\ ${ }^{1}$ Physical Department, Faculty of Science, Thi Qar University, Thi Qar, Iraq. \\ ${ }^{2}$ Electrical Department, Al Furat Al Wast University, Technical Institute of Samawa, Samawa, Iraq.
}

\section{Email address:}

asabah_sh2003@yahoo.com (S. M. M. al Mutoki)

\section{To cite this article:}

S. AbdulAmohsin, Sabah Mohammed Mlkat al Mutoki, M. Mohamed. ZnO Nanowire/N719 Dye/Polythiophene-SWNT Nanocomposite Solid State Dye Sensitized Solar Cells. Automation, Control and Intelligent Systems. Special Issue: Artificial Nano Sensory System. Vol. 3, No. 2-1, 2015, pp. 12-17. doi: 10.11648/j.acis.s.2015030201.13

\begin{abstract}
We designed and fabricated high efficiency solid state dye sensitized solar cells based on vertical $\mathrm{ZnO}$ nanowire arrays by utilizing a mixture paste of LiI, PMII and solid iodine as electrolyte. Poly thiophene -single wall carbon nanotube (PT-SWNT) composites were synthesized on FTO glass by in situ polymerization and employed as counter electrode to replace the conventionally used expensive Pt electrode. The initial results showed the power conversion efficiency of $2.87 \%$ from the device with PPy-SWNT composite coated on FTO glass as counter electrode.
\end{abstract}

Keywords: Nanocomposite, SWNT, PT, Solid State Dye Sensitized Solar Cell

\section{Introduction}

The efficiencies of dye-sensitized solar cells (DSCs) recently have been reported up to $12 \%$ (Yu et al., 2010) since the DSCs using nanocrystalline structures were published by O'Regan and Grätzel (1991)[1,2]. DSCs have generated excitement because they consist mainly of nontoxic materials and offer a low-cost processing route (such as coating or printing) to thin-film device fabrication. Furthermore, they can be adapted for a variety of indoor and outdoor applications, and achieve high performance with minimal environmental impact. A DSC operates based on the interactions between the cell's anode and cathode, and a film of titanium oxide nanoparticles covered with light-sensitive dye molecules[3,4]. An electrolyte, usually in form of iodide, fills the space between the $\mathrm{TiO} 2$ nanoparticles, and helps transfer electrons from the cathode to the dye molecules[5]. The fabrication of DSCs typically requires an electrolyte that enables high charge-collection efficiencies and high opencircuit voltages. The iodide electrolyte is particularly attractive in this regard as its oxidized form, $\mathrm{I}^{3-}$, does not readily accept electrons from the titania surface[6]. This minimizes charge recombination in functioning cell devices. Despite all the benefit and relatively high conversion efficiencies for solar energy, DSCs typically have durability issues associated with the liquid electrolyte, such as electrode corrosion or electrolyte leakage[7-10]. These issues have lead to a significant decrease in conversion efficiency, making these solar cells unsuitable for long-term use. However, the charge recombination in ss-DSCs is 1 to 2 orders of magnitude faster compared to liquid-electrolyte DSCs, which should reduce the achievable open-circuit voltage by 100 to $200 \mathrm{mV}$.

Currently, the best performing ss-DSCs achieve power conversion efficiencies of up to $7.2 \%,[11]$ thus still lagging behind DSCs based on a liquid electrolyte, which are now over $12 \%$.[12] The underperformance of ss-DSC is thought to be associated with three main challenges: i) limited porefilling of the mesoporous $\mathrm{TiO} 2$ with the HTM to ensure the optimum composition of the photoactive layer, 13-16] ii) panchromatic absorption of light, which is currently limited by the maximal film thickness of well-performing ss-DSCs, [17] and iii) efficient charge generation and transport from the excited dye to maximize the current output from the sunlight.[18-25] While issues with efficient charge generation have been extensively addressed (though not resolved) in earlier work, [18-24]the related challenges of effective pore-filling and sufficient panchromatic absorption remains open.

Our purpose is to get high efficiency solid state dye sensitive solar cells base on $\mathrm{ZnO} \mathrm{NW} / \mathrm{N} 719$ dye/PT ,or nanocomposite PT + SWCNTS 
I used1- pristine PT by electrochemical method, PT+SWCNTS (10 wt \%) , and Pristine SWCNTS

\section{Experimental}

\subsection{Materials}

\subsubsection{Materials Synthesis}

The vertically aligned $\mathrm{ZnO} \mathrm{NW}$ arrays were fabricated on FTO glass substrates (SPI Supplies) by a low temperature electrochemical method.[20 ]They were typically prepared in a two-step process. First, a layer of $\mathrm{ZnO}$ thin films was grown on the FTO substrates by using $0.05 \mathrm{M}$ Zinc nitrate (Alpha Aessar) dissolved in a mixture of de-ionized water and methanol (50:50). The growth temperature was kept at $70{ }^{\circ} \mathrm{C}$ and the growth time was $5 \mathrm{~min}$ under an applied voltage of $-2.5 \mathrm{~V}$ with two Au electrodes, one of which was connected to the FTO glass substrate as working electrode and the other one was used as a counter electrode. A thin film of about 100-200 nm can be deposited. In the second step, $\mathrm{ZnO} \mathrm{NW}$ arrays were grown on top of the $\mathrm{ZnO}$ thin film using an electrolyte containing $0.01 \mathrm{M}$ Zinc nitrate and 0.01 $\mathrm{M}$ hexamethylenetetramine in de-ionized water. The growth was performed at $95{ }^{\circ} \mathrm{C}$ with an applied potential of $-2.6 \mathrm{~V}$ between working and counter electrodes.

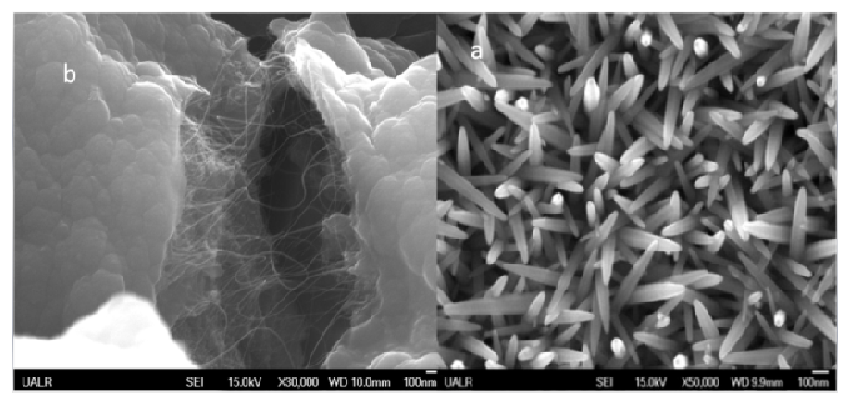

Fig. 1. SEM images of $\mathrm{ZnO}$ nanowire arrays (a), Nanocomposite materials PT-SWNTS (b)

As seen from Fig. 1 (a), the nanowires with an average diameter of 100-200 $\mathrm{nm}$ are vertically aligned on the substrate show the two components mixed and distributed uniformly in each other (Fig.1 (b)).

Thiophene monomer was distilled twice under reduced pressure before use, and dissolved into a acetonitral to make a $0.1 \mathrm{M}$ solution. The polyThiophene was synthesized with a galvanostatic step method at a constant voltage of $2 \mathrm{~V}$. The working electrode was a commercial ITO-glass with a surface area of $1.5 \mathrm{~cm}^{2}$. A Platinum wire was used as a counter electrode. The amount of the electrodeposited polythiophene was estimated by weighing the working electrode before and after the electro deposition. Figure 1 displays a schematic diagram of the electrochemical cell for in situ polymerization.

$\mathrm{TiO}_{2}$ nanopartical and PT were brought into contact by sandwiching them to create the solid State Dye Sensitive solar cells . To ensure intimate contact with no leak between the $\mathrm{TiO}_{2}$ and the PT, the two films were sandwiched right after the electrochemical process when the PT was still wet to avoid the oxidation for thin film of polythiophene. A schematic diagram of the fabricated device is illustrated in Figure 3. Current density-voltage ( $\mathrm{J}-\mathrm{V})$ characteristics have been investigated in the dark and under illumination using an AM1.5 sunlight simulator. Irradiation was achieved from the $\mathrm{TiO}_{2}$ side and from the nanocomposite side explained in figure 4 .

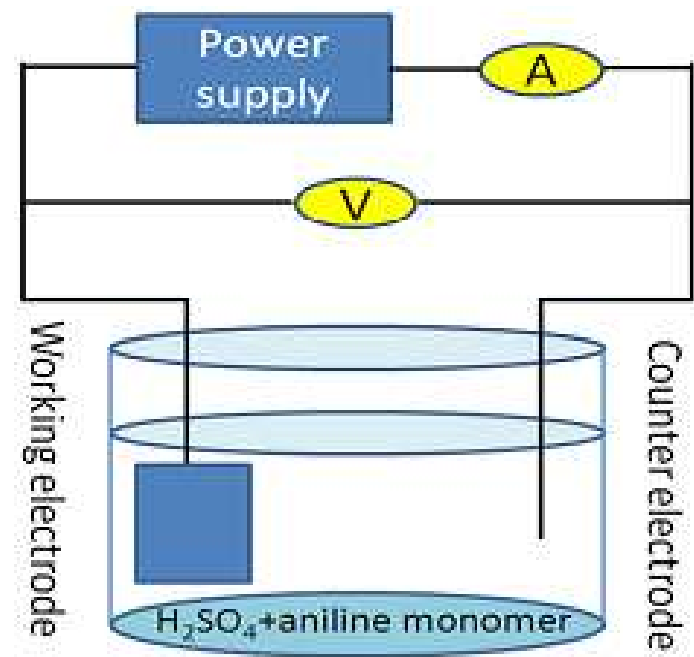

Fig. 2. Schematic diagram of the electrochemical cell used to prepare the PT thin film.

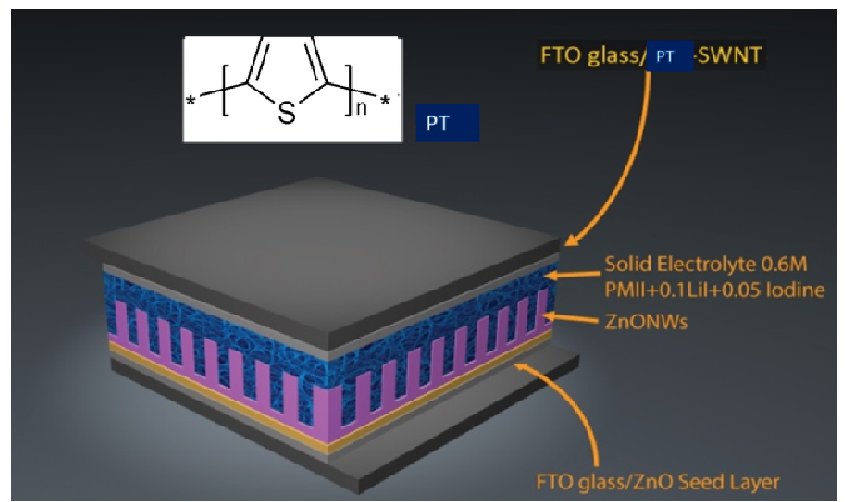

Fig. 3. Schematic diagram of the ZnO nanowire/N719 dyel PolythiopheneSWNT nanocomposite solid state dye sensitized solar cells.

\subsection{Fabrication of ss-DSCS}

SWCNTS ,Iodine,1-methyle-3-propyl imidazolium iodine (PMII) ,Zinc nitrate ,Hexamethylentetramine was obtained from cheap tube and Aldrich respectively, Using airbrushing technique to deposit SWCNTs on FTO glass, then deposit polythiophene by electrochemical on top of SWCNTS to get good penetration of PT with SWCNTS, put two drop of organic solvent electrolyte ( mixture of $0.1 \mathrm{M}$ LiI,0.6 MPMII,0.005 $\mathrm{M} \mathrm{I}_{2}$ ) after $5 \mathrm{sec}$ the electrolyte will dry and make sandwich them ,finally the Solid State Dye Device ready to measure $\mathrm{I}-\mathrm{V}$, We have three device PT ,SWCNTS , and Nano composite to compare among those Devices to study effect of Nano composite on Solar Cells performance. 


\subsection{Characterization}

Various techniques were employed to characterize the obtained materials in this study, including SEM, UV-Vis absorption, FTIR, and Raman spectroscopy. Raman scattering was collected at room temperature using a Horiba Jobin Yvon LabRam HR800 spectrometer equipped with a charge-coupled detector and a He-Ne laser (633 nm) as excitation sources. Raman shifts were calibrated with a silicon wafer at the $521 \mathrm{~cm}^{-1}$ peak. The optical absorption of the composite films was measured by using a Shimadzu double beam spectrophotometer UV-3600. The Fourier transform infrared (FTIR) spectra were collected on a Nicolet MAGNA-IR 550 Series 2 Spectrometer with a resolution of 8 $\mathrm{cm}^{-1}$. The reported spectra were averaged for 32 scans.

Current density-voltage $(\mathrm{J}-\mathrm{V})$ characteristics were investigated in the dark and under illumination using a solar simulator at AM1.5 $\left(\sim 100 \mathrm{~mW} / \mathrm{cm}^{2}\right)$ inside a glove box in a nitrogen environment. Illumination was on the $\mathrm{TiO}_{2}$ side. The devices were irradiated in an area of $3 \times 3 \mathrm{~mm}^{2}$ and data were recorded using a Keithley 2400 source meter.

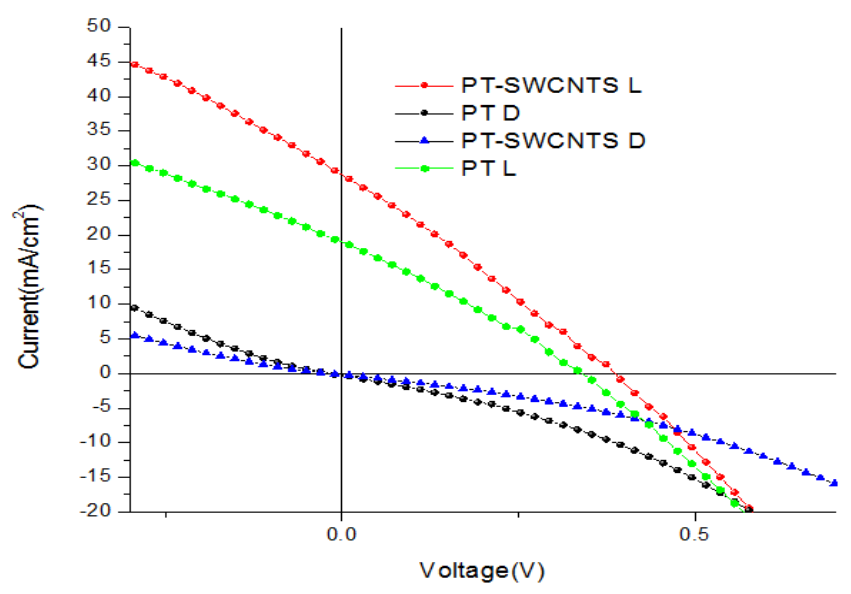

Fig. 4. Photocurrent-voltage characteristics of DSSCs with PT (solid line) and Pt (dash line) counter electrodes under $100 \mathrm{~mA} / \mathrm{cm}^{2}$ light irradiation.

\section{Results and Discussion}

I study Solid state dye sensitized solar cells base on $\mathrm{ZnO}$ NW arrays modified by N719, and PANI +0.6 M of PMII ( 1methyl-3-propyl imidazolium iodide) and $0.1 \mathrm{LiI}+0.05$ Iodine as a solid electrolyte where The prepare of $\mathrm{ZnONW}$, PANI describe with attached, and immerse the $\mathrm{ZnO} N W$ in ethanol solution of N719 dye for 3 days using electrochemical polymerization of PANI on ITO glass then add one drop of $0.6 \mathrm{M}$ of PMII ( 1-methyl-3-propyl imidazolium iodide) and $0.1 \mathrm{LiI}+0.05$ Iodine as a solid electrolyte then sandwich them after put separator the efficiency improve from 1.78 to $2.90 \%$

\subsection{Experimental Details}

\subsubsection{J-V Results}

This Figure IV Illumination of Nanocomposite of PT
+SWCNTS ,PT,SWCNTS for Solid state dye sensitized solar cells containing ionic liquid and nanocomposite solar cells

As seen in Fig. 4, the performance of the solid state dyesensitized solar cells was improved by using nanocomposite SWNTs-PT as HTM. Under illumination AM1.5G, the cell with SWNTs has higher output current as compared to the on pristine PT. The short-circuit current density, $\mathrm{J}_{\mathrm{SC}}$, and the open-circuit voltage, $\mathrm{V}_{\mathrm{OC}}$ are significantly improved which increased from 19 to $28 \mathrm{~mA} / \mathrm{cm}^{2}$ and 0.33 to 0.39 respectively in the other side the fall factor and efficiency increase from $32 \%$ to $42 \%$ and 1.78 to $2.9 \%$ respectively by using SWNTs. The experimental data demonstrate that the use of SWNTS helps to improve the solar cell performance with an increased conversion efficiency from 1.78 to 2.9 . This observation is explained by the significantly increased contact area between the SWNT-PT (HTM) and the paste which facilitates efficient charge transportation in the solar cell. We demonstrated that the PPY-SWNT composites are suitable to improve the stability and efficiency for fabricating high efficiency Solid state dye

Although $J_{s c}$ from ITO side illumination is lower than that from FTO side illumination, the $V_{o c}$ was similar and do not depend on the direction of incident photon. $V_{o c}$ could be considered as a result in the interfacial kinetics between injected electrons with back transfer electrons. Under opencircuit conditions, the rate of injected electrons from dyes is balanced by that of back transfer electrons from $\mathrm{TiO}_{2}$ to spiro-MeOTAD or dyes. Assuming dye regeneration is efficient, recombination from $\mathrm{TiO}_{2}$ to dye is negligible and thus $V_{o c}$ is given by Bisquert et al., 2004[25],

$$
V_{\propto c}=\frac{k T}{q} \operatorname{In}\left(\frac{J_{s c} \tau_{0}}{q \alpha n_{o}}\right)
$$

where $k$ is Boltzmann's constant, $T$ is the temperature, $q$ is electronic charge, $J_{s c}$ is the short-circuit current, $\tau_{0}$ is an electron lifetime, $\alpha$ is the ratio of surface electrons concentration participated in recombination to electrons in the $\mathrm{TiO}_{2}$, and $n_{o}$ is the electron concentration in the conduction band in the dark. Since the optical process mainly dominates our current output, the $J_{s c} / n_{o}$ in principle remained constant measurement. From the equation, we believe our identical $V_{o c}$ from different sides illumination is a measure of the electron lifetime.

\subsection{Optical Properties of Materials}

The photoluminescence spectra of $\mathrm{ZnO} \mathrm{NW}$ (blue line) , and N719 grafted $\mathrm{ZnO} \mathrm{NW}$ (Red line) in methanol, excited at $325 \mathrm{~nm}$ at the same optical density the figure 5 indicates the photoluminescence was quenched in both UV and visible regions when the N719 grafted to the $\mathrm{ZnO}$ nanowires to be sensitized .we can conclude the possibility of the dye N719 resonance energy transfer which causes the static quenching due to dye aggregation on to the $\mathrm{ZnO} \mathrm{NW}$ surface.thus, we attribute this photoluminescence quenching to the efficient photoinduced electron transfer from the dye N719 to the $\mathrm{ZnO} \mathrm{NW}$. 


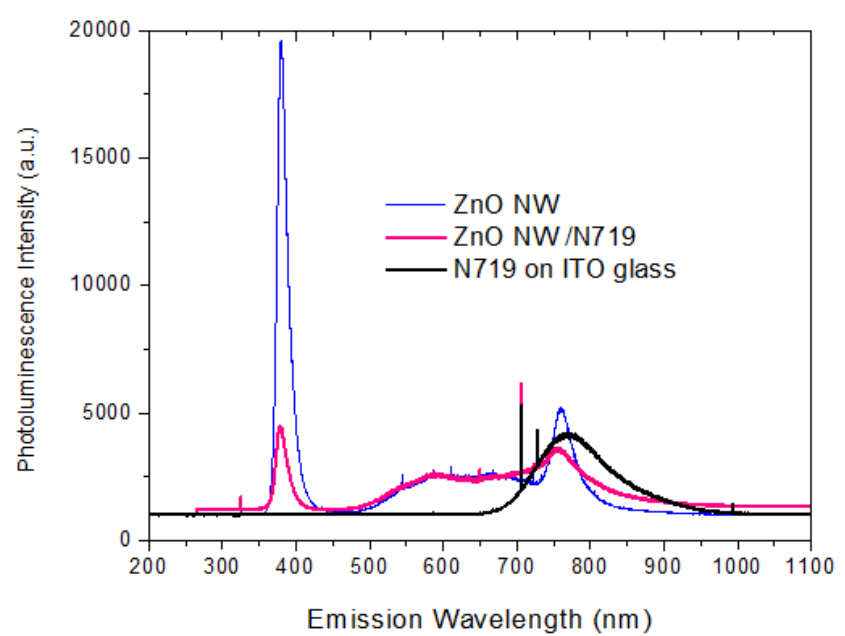

Fig. 5. The photoluminescence spectra of $\mathrm{ZnO}$ nanowires, and $\mathrm{ZnO}$ nanowires coated with N719, and N719 on ITO glass.

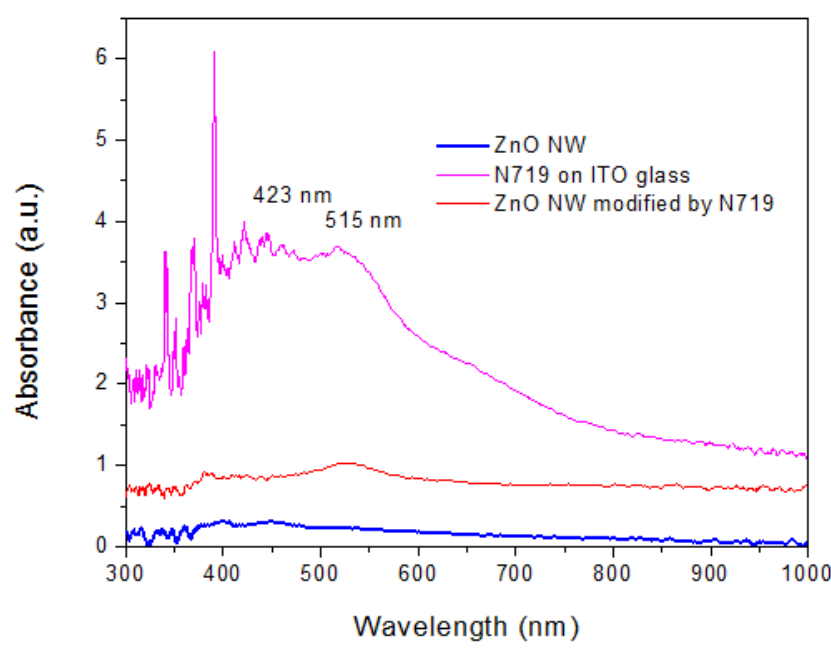

Fig. 6. The optical absorption spectra of ZnO nanowires, and N719 on ITO glass, and ZnO nanowires modified by $N 719$

In order to understand the reasons behind the increased PCE by N719 dye modification, where explored their optical properties as seen in the figure 6 where there are 2 main new peaks (423 nm to $515 \mathrm{~nm})$.

The modification of $\mathrm{ZnO} \mathrm{NW}$ thin film with N719 dye exhibits a strong increase in absorption around 423nm -515 $\mathrm{nm}$, which is attributed to the additional absorption of the coated porphyrin on $\mathrm{ZnO}$ surface .

Crystallography

Figure 7 presents the X-Ray diffraction (XRD) spectra of N719 dye on ZnO NW (black curve), and N719 on ITO glass (Red curve) ,and ITO glass (Pink) the peak at centered at 2 theta $31.11^{0}$ and $36.13^{0}$ are from ITO glass, and the strong peaks 2 theta $-34.2^{0}$ is from $\mathrm{ZnO} \mathrm{NW}$ surface .XRD results explain that the final crystalline structure does not effect after modified by N719 dye and aggregation of N719 dye to ZnO NW surface introduce no change in crystalline structure of ZnO NW

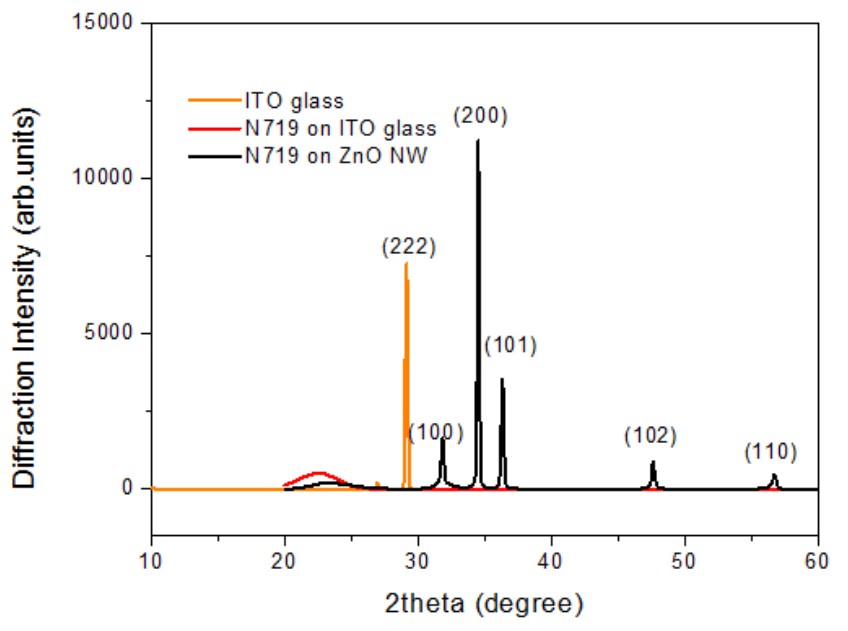

Fig. 7. The XRD patterns of ITO glass, N719 on ITO glass and N719 on ZnO nanowires.

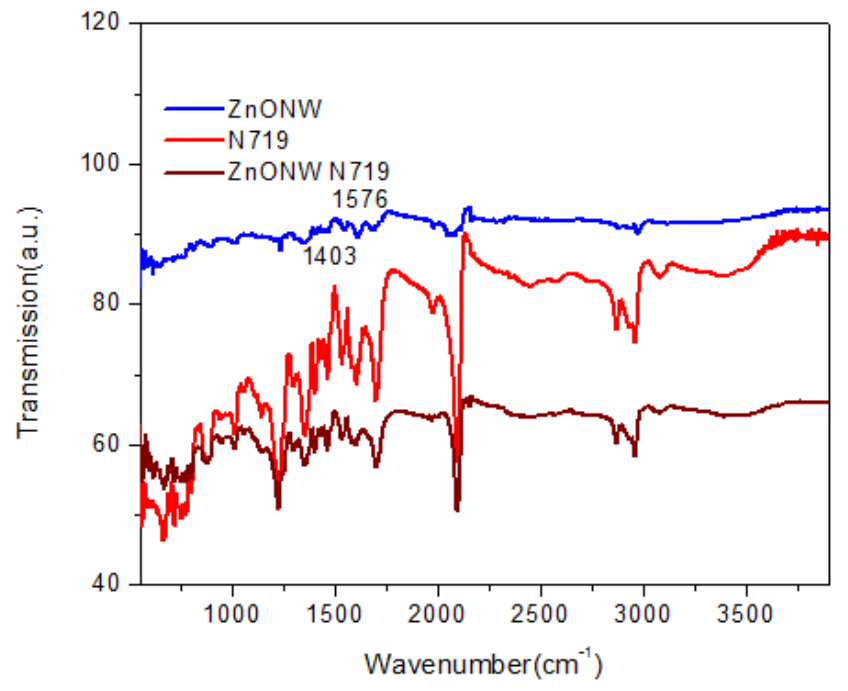

Fig. 8. FTIR of ZnONW,ZnONW N719, and N719

Figure 8 Shows the FTIR spectrum of the $\mathrm{ZnO} \mathrm{NW}$ synthesized by electrochemical method,which was aquired in the range $400-4000 \mathrm{~cm}^{-1}$ correlated to metal oxide bond ( $\mathrm{ZnO}$ ). from this FTIR for $\mathrm{ZnO} \mathrm{NW}$ in addition to $\mathrm{ZnO} \mathrm{NW}$ modified by N719 Dye the peaks in the range of 1400-1500 $\mathrm{cm}^{-1}$ corresponds to $\mathrm{C}=\mathrm{O}$ bonds .The adsorbed band at 1626 $\mathrm{cm}^{-1}$ is assigned $\mathrm{O}-\mathrm{H}$ bending vibration the binding between the dye molecules (N719) and the surface of ZnO NW was investigated by FTIR spectra of the dye modified $\mathrm{ZnO}$ NW . The solar cells efficiency depend on charge injection process and its highly depending on bonding structure of the dye molecules on the $\mathrm{ZnO} \mathrm{NW}$.In addition ,the electron transfer in Solid state dye sensitive solar cells is strongly influenced by electrostatic and chemical interaction between $\mathrm{ZnO} N W$ surface and the adsorbed dye molecules[27] Figure 8 shows the FTIR spectra of N719 on ZnO NW compared to the curve of the dye solution.Absorption at $2105 \mathrm{~cm}^{-1}$ of $\mathrm{N} 719$ dye is attributed to the SCN stretch model of N-bounded SCN ligand [28,27] The IR spectra were observed at $1370 \mathrm{~cm}^{-}$ ${ }^{1}, 1610 \mathrm{~cm}^{-1}$ is consistent with the bidentate coordinate .The same results were reported that the coordination of N719 dye 
on $\mathrm{ZnO} \mathrm{NW}$ occurs mainly by contribution of unidentate and partially by bidentate linkage [26-28]

\section{Conclusion}

In brief, in order to develop new type of counter electrode to replace the conventional used expensive Pt electrode used in dye sensitized solar cells, we synthesized polythiophenesingle wall carbon nanotube (PT-SWNT) composites on FTO glass by in situ electrochemical polymerization. $\mathrm{ZnO}$ nanowire arrays were vertically gorwn on $\mathrm{ZnO}$ buffered FTO glass and utilized as a $3 \mathrm{D}$ photoanode. We designed and fabricated high efficiency solid state dye sensitized solar cells by sandwiching the two parts and utilizing a mixture paste of LiI, PMII and solid iodine as electrolyte. The initial results showed the power conversion efficiency of $2.87 \%$ from the device with PT-SWNT composite coated on FTO glass as counter electrode, which is significantly higher that built with PT. The enhanced light conversion is due to improved charge transport in the PT-SWNT composites. The structure of the vertical $\mathrm{ZnO}$ array also benefits photon absorption.

\section{References}

[1] B. O'regan and M. Grfitzeli, "A low-cost, high-efficiency solar cell based on dye-sensitized," Nature 353, 24 (1991).

[2] G. H. Guai, Y. Li, C. M. Ng, C. M. Li, and M. B Chan-Park, " $\mathrm{TiO}_{2}$ composing with pristine, metallic or semiconducting single-walled carbon nanotubes: which gives the Best Performance for a dye-sensitized solar cell," ChemPhysChem 13 (10), 2566-2572 (2012).

[3] Y. Xu, C. He, F. Liu, M. Jiao, and S. Yang, "Hybrid hexagonal nanorods of metal nitride clusterfullerene and porphyrin using a supramolecular approach," Journal of Materials Chemistry 21 (35), 13538-13545 (2011).

[4] J. H. Zhao, X. C. Yang, M. Cheng, S. F. Li, and L. C. Sun, "New Organic Dyes with a Phenanthrenequinone Derivative as the pi-Conjugated Bridge for Dye-Sensitized Solar Cells," $J$. Phys. Chem. C 117 (25), 12936-12941 (2013).

[5] V. Tjoa, J. Chua, S. S. Pramana, J. Wei, S. G. Mhaisalkar, and N. Mathews, "Facile Photochemical Synthesis of Graphene-Pt Nanoparticle Composite for Counter Electrode in Dye Sensitized Solar Cell," Acs Applied Materials \& Interfaces 4 (7), 3447-3452 (2012)

[6] G. Yue, J. Wu, Y. Xiao, J. Lin, M. Huang, and Z. Lan, "Application of poly(3,4-ethylenedioxythiophene): polystyrenesulfonate / polypyrrole counter electrode for dyesensitized solar cells," The Journal of Physical Chemistry C 116 (34), 18057-18063 (2012).

[7] J. Zang, C. M. Li, S.-J. Bao, X. Cui, Q. Bao, and C. Q. Sun, "Template-free electrochemical synthesis of superhydrophilic polypyrrole nanofiber network," Macromolecules 41 (19), 7053-7057 (2008).

[8] S. Thomas, T.G. Deepak, G.S. Anjusree, T.A. Arun, S. V. Nair, and A. S. Nair, "A review on counter electrode materials in dye-sensitized solar cells," Journal of Materials Chemistry A (2014).
[9] S. Siriroj, S. Pimanpang, M. Towannang, W. Maiaugree, S. Phumying, W. Jarernboon, and V. Amornkitbamrung, "High performance dye-sensitized solar cell based on hydrothermally deposited multiwall carbon nanotube counter electrode," Applied Physics Letters 100 (24), 243303-243303-243304 (2012).

[10] W. Jarernboon, S. Pimanpang, S. Maensiri, E. Swatsitang, and V. Amornkitbamrung, "Effects of multiwall carbon nanotubes in reducing microcrack formation on electrophoretically deposited $\mathrm{TiO}_{2}$ film," Journal of Alloys and Compounds 476 (1), 840-846 (2009).

[11] K. Murakoshi, R. Kogure, Y. Wada, and S. Yanagida, "Fabrication of solid-state dye-sensitized $\mathrm{TiO}_{2}$ solar cells combined with polypyrrole," Solar Energy Materials and Solar Cells 55 (1), 113-125 (1998).

[12] T. Kitamura, M. Maitani, M. Matsuda, Y. Wada, and S. Yanagida, "Improved solid-state dye solar cells with polypyrrole using a carbon-based counter electrode," Chemistry Letters 30 (10), 1054-1055 (2001).

[13] R. Cervini, Y. Cheng, and G. Simon, "Solid-state Ru-dye solar cells using polypyrrole as a hole conductor," Journal of Physics D: Applied Physics 37 (1), 13 (2004).

[14] H. Hlura, T.W. Ebbesen, T. Tanigaki, H. Takahashi, Chem. Phys. Lett. 202, 509(1993).

[15] W. A. de Heer, W.S. Bacsa, A. Chatelain, T. Gerfin, R. Humphrey-Baker, L. Forro, and D. Ugarte, "Aligned carbon nanotube films: production and optical and electronic properties," Science 268, 845-847 (1995).

[16] J. S. Liu, T. Tanaka, K. Sivula, A. P. Alivisatos, and J. M. J. Frechet, "Employing end-functional polythio-phene to control the morphology of nanocrystal-polymer composites in hybrid solar cells," Journal of the American Chemical Society 126 (21), 6550-6551 (2004).

[17] Y.-Ch. Liu, B.-J. Hwang, W.-J. Jian, and R. Santhanam, "In situ cyclic voltammetry-surface-enhanced Raman spectroscopy: studies on the doping-undoping of polypyrrole film," Thin Solid Films 374 (1), 85-91 (2000).

[18] J. Duchet, R. Legras, and S. Demoustier-Champagne, "Chemical synthesis of polypyrrole: structure-properties relationship," Synthetic Met 98 (2), 113-122, (1998).

[19] A. B. Gonçalves, A. S. Mangrich, and A. J. G. Zarbin, "Polymerization of pyrrole between the layers of $\alpha$-Tin (IV) Bis (hydrogenphosphate)," Synthetic Met 114 (2), 119-124 (2000).

[20] R.H Friend, D.D.C Bradley, and P.D. Townsend, "Photoexcitation in conjugated polymers," Journal of Physics D: Applied Physics 20 (11), 1367 (1987).

[21] G Harbeke, D Baeriswyl, H Kiess, and W Kobel, "Polarons and bipolarons in doped polythiophenes," Physica Scripta 1986 (T13), 302 (1986).

[22] R. Yang, W. H. Smyrl, D. F. Evans and W. A. Hendrickson, J. Phys. Chem, 96, 1428(1992).

[23] M. J. Antony and M. Jayakannan, J. Phys. Chem. B, 111, 12772(2007).

[24] P. Galář, B. Dzurňák, P. Malý, J. Čermák, A. Kromka, M. Omastová, and B. Rezek, "Chemical Changes and Photoluminescence Properties of UV Modified Polypyrrole," Int. J. Electrochem. Sci. 8, 57-70 (2013). 
[25] Bisquert.J, and Peter.C .Journal of physical chemistry letters,vo.51,issue 1,205-207.

[26] Hwang, K. J.; Yoo, S. J.; Kim, S. S.; Kim, J. M.; Shim, W. G.; Kim, S. I.; Lee, J. W. J. Nanosci. Nanotechnol. 2008, 8, 4976.
[27] Leon, C. P.; Kador, L.; Peng, B.; Thelakkat, M. J. Phys. Chem. $B$ 2006, 110(17), 8723 .

[28] Finnie, K. S.; Bartlett, J. R.; Woolfrey, J. L. Langmuir 1998, 14,2744 